\title{
Gender sensitivity in pedagogical practices in secondary education in
}

\section{Bhutan}

\author{
Yuden Yuden ${ }^{1}$, Sonam Chuki ${ }^{1}$ \& Tshewang Dorji*2
}

* Corresponding author

E-mail: tshewangtshewang@gmail.com

1. Royal Education Council, Paro, Bhutan

2. Dechencholing Higher Secondary School, Thimphu Thromde, Bhutan

(1) https://orcid.org/0000-0003-0651-5403

\section{Article Info}

Received: August 12, 2020

Revised: October 9, 2020

Accepted: November 18, 2020

L0.46303/repam.2020.3

\section{How to cite}

Yuden, Y., Chuki, S., \& Dorji, T. (2020). Gender sensitivity in pedagogical practices in secondary education in Bhutan. Research in Educational Policy and Management, 2(2), 38-51.

https://doi.org/10.46303/repam.2020.3

\section{Copyright license}

This is an Open Access article distributed under the terms of the Creative Commons Attribution 4.0 International license (CC BY 4.0).

\begin{abstract}
The terrain of gender inequities in education has seen many changes in recent times. The purpose of the study was to find out the gender sensitivity in pedagogical practices in secondary education in Bhutan. The study was qualitative and used nonprobability convenient sampling techniques. The study used classroom observations to gain the first-hand experience of a normal classroom and focus group discussions with teachers and students to get in-depth views. The classroom observation and focus group discussion data were analysed using the process of emerging themes. The study revealed that teachers were not gendered sensitive in pedagogical practices in the secondary education level. There were challenges in understanding gender in education both by teachers and students. There was neither gender awareness nor conscious effort made by teachers to address gender inequality in the classroom. A gender-responsive education that supports the realization of student full potential requires the teachers to practice gender-sensitive pedagogy. To address the issue, there is an immediate need for gender awareness and sensitization among teachers and school leaders. Teacher education colleges should introduce modules such as gender and education or gender and development so that the classroom environment is gender-sensitive and gender friendly.

KEYWORDS

Secondary education; gender sensitivity; pedagogical practices; teachers; students.
\end{abstract}




\section{INTRODUCTION}

In 2017, the Gender Inequality Index value of Bhutan was 0.476, ranking Bhutan 117 out of 160 countries (UNDP, 2018). 6\% adult women have reached at least a secondary level of education compared to men with $13.7 \%$. In the parliament and the local government, women representative at decision making is less than men (with $15.27 \%$ in parliament and $11.6 \%$ in local government). There are $11.2 \%$ women in the civil service at policymaking or executive level (GNHC, 2019). A report of GNH analysis in Bhutan indicates that men were happier than women.

The female unemployment rate was estimated at $6.1 \%$ as compared to $3.6 \%$ for males in the urban areas, specifically, in the age group of 15-24, urban females are found more unemployed than urban males (NSB, 2017). Only 6.1\% of female labour has paid regular jobs compared to $17.8 \%$ male labour force. $81 \%$ of female labour work is unstable, unprotected, and unregulated low paying jobs (NSB \& ADB, 2012). 59.3\% of females were employed and engaged in the agriculture sector compared to males at $34.2 \%$ (NSB, 2017). Therefore, it is very important to deliver high-quality teaching in schools and raise the bar of learning for the girls (iDiscoveri Education \& REC, 2009). Bhutan aims of becoming a knowledge-based society through providing quality education in schools, but quality education lags behind globally (MoE, 2014). Although the gender gap is closing, Bhutan is still far from reaching gender equality in education, health, labour force, and decision making. Where schools fail to deliver quality education, girls are dropping out early (UNESCO, 2014). Education for girls must be seen as part of a much larger societal issue (UNESCO, 2004) in overcoming gender inequality.

UNESCO (2000) fully recognize gender-sensitive education as one of the factors that enable the vision of Education for All to translate into reality. The major challenges concerning education and training include promoting greater female enrolment in higher education while ensuring continuing efforts toward gender parity at the secondary level. However, graduates from higher education are unable to meet the admission criteria of top tier higher education institutions abroad, particularly for professional courses. This reflects the poor learning outcomes of the education system not being commensurate to the requirements of youth today (GNHC, 2019). For example, in 2006, out of the 138 slots available for undergraduate programs abroad, only 26 girls were selected based on the required qualifications. Other elements of gender equality in education have received less attention, including equality of learning outcomes. Girls' poor performance in maths and science is a constraint on participation and options at higher levels (ADB, 2014). Despite the initiatives for equal opportunity policies in many schools aimed to empower girls and many teachers being keen to redress gender inequality to enable students' potential, equal opportunities for girls are found less in many schools even today (Warrington \& Younger, 2020).

\section{Objective of the Study}

The objectives of the study were to understand the classroom dynamics of secondary schools to ascertain the reasons for gender gaps and recommend strategies to enhance gender-sensitive 
pedagogical practices in secondary education.

\section{Research Question}

What are the common classroom pedagogical practices and understanding of gender in middle and higher secondary schools?

\section{LITERATURE REVIEW}

Women across the globe are treated unequally and placed less value on their lives and denied rights, opportunities, and resources due to gender (Reeves \& Baden, 2000). In Bhutan, it is an age-old belief that 'a woman has to live nine lives to be born a man' (UNESCO, 2009) which in local terms is called Kye rab gu. Gender disparity is commonly found between boys and girls in terms of access, retention, and learning achievement. It is important to emphasize more on quality education for both boys and girls (Chisamy et al., 2011). In Bhutan, gender parity is achieved at the primary education level but gender disparity at secondary and higher education remains a challenge (Dorji, 2017). In Bhutan, there have been significant strides in the net enrolment and primary education completion and has substantial progress in access to secondary level education (UNICEF, 2012). The Adjusted Net Enrolment Rate (ANER) was 96.8\% (97.4\% boys and $91.1 \%$ girls) in 2018. Similarly, Gross Enrolment Ratio (GER) in 2018 for class PP-X and VII-XII was $10.3 \%$ and $89.3 \%$ respectively. However, there is a need for emphasis on the creation of strong demand for girls' in secondary education and provide strong support for the secondary learning environment for all boys and girls (UNICEF, 2017).

Duckworth and Seligman (2006) found that boys tend to obtain a higher score on the standardized test while girls tend to get higher grades. National and international results show boys have a higher test score in mathematics while girls have higher test scores in reading (Marks, 2007). In the class XII Bhutan Higher Secondary Education Certificate examinations, on average, girls are performing poorly compared to boys (Dorji, 2017). Girls are doing marginally better in English, Economics, Commerce, and Accounts while boys are performing better than girls in subjects like Mathematics, Science, Computer Studies, History, and Geography. Overall, the low scores by both boys and girls show a lower level of learning outcomes (BCSEA, 2014).

The Annual Status of Student Learning (REC, 2010 \& 2011) studies show that boys outperformed girls in mathematics in class IV, VI, and VIII while girls outperformed boys in English. There were fewer numbers of girls studying science as compared to a greater number of girls pursuing Arts and Commerce. Overall, at the higher secondary level, female enrolment was lower than that of boys with the total number of girls standing at 8,604 compared to 8,793 boys (MoE, 2014). PISA-D Report (BCSEA, 2019) reveals that boys performed better than girls. Girls outperformed boys in Reading Literacy and Mathematical Literacy. However, both boys and girls performed almost at par in Scientific Literacy. Bhutanese students performed better in items of lower cognitive skills and significantly found Bhutanese students were below the Organisation for Economic Cooperation and Development (OECD) average and of the best 
education systems in Asia. According to Hodges (2001), the male and female disparity is found in science courses, medicine, veterinary, English, and technology-based courses.

Gender-responsive classroom set-ups play a crucial role in the teaching-learning process. However, many schools face difficulty in classroom management due to the sheer size of students and limited classroom size (FAWE, 2005). Teachers and educationists must be sensitized on the needs and situations of learners of both boys and girls (UNESCO, 2004). Studies show that a gender-friendly classroom environment can build harmonious relations between boys and girls at different stages of schooling.

So far, only one study was carried out on gender sensitivity in pedagogical practices in Bhutan. In the study by Dorji (2020), the Gender-responsive pedagogy awareness and practice: A case of higher secondary school under Thimphu Thromde in Bhutan reveal that teachers teaching in higher secondary schools did not know about gender and gender-responsive pedagogy. Teachers were not seen to practice gender-responsive pedagogy in the classrooms and their lesson plans did not highlight elements of gender. The teachers' use of language and classroom management did not reflect gender awareness. The study recommended the Ministry of Education to provide orientation workshops and conduct seminars to in-service teachers on gender to create awareness. The study also recommended the Colleges of Education of the Royal University of Bhutan to integrate gender in the teacher education programs and for its faculty model gender-sensitive pedagogy.

Teachers' attitudes, actions, and words can discourage girls and hamper their progress in schools. There is a lack of gender sensitivity training in teacher training courses. Teachers need the training to understand and recognize their attitudes, perceptions, and expectation regarding gender thereby teacher interaction with students do not harm boys' and girls' learning experiences and achievement (UNESCO, 2014).

\section{METHOD}

\section{Research Design}

The study was exploratory and qualitative comprising of classroom observations and Focus Group Discussions (FGD). So far only one study has been done on the gender sensitivity pedagogical practices in Bhutan.

\section{Participants}

Teachers and students in the secondary school under the Ministry of Education.

\section{Sample Design}

A non-probability convenience sampling was used to identify schools. Two schools each under Thimphu Thromde, Samdrup Jongkhar, Bumthang and Paro Dzongkhags making a total of eight 
schools participated in the study. The selected schools were either semi-urban or urban by the nature of the location.

\section{Data Collection}

\section{Classroom Observation}

The classroom observations were carried out to gain the first-hand experience with a normal classroom and identify common patterns in structure, instructional practice, displays, and how a teacher consciously practices gender-sensitive pedagogy. For example, a teacher may not realize that they usually ask boys questions about mathematics and how many times they call on boys and not girls.

Classes IX to XII were selected, as the learners are adolescents who experience genderbased identities. 10 male and six female teachers volunteered to be observed. Two researchers observed classes ranging from 45 to 50 minutes in subjects such as Economics, English, History, Physics, Geography, Mathematics, Chemistry, and Biology. The researchers used observation forms that covered mapping student sitting, number of times the teacher called out boy and girl students, and teaching-learning materials used.

\section{Focus Group Discussion}

24 teachers and 44 students of four middle and higher secondary schools participated in eight separate FGD.

Table 1: Number of teachers and students for the FGD

\begin{tabular}{llllll} 
SI. No. & Schools & Teachers & \multicolumn{2}{l}{ Students } \\
\hline & & Male & Female & Male & Female \\
\hline $\mathbf{1}$ & Higher Secondary School & 3 & 3 & 6 & 5 \\
\hline $\mathbf{2}$ & Middle Secondary School & 3 & 3 & 6 & 5 \\
\hline $\mathbf{3}$ & Central School I & 3 & 3 & 4 & 7 \\
\hline $\mathbf{4}$ & Central School II & $\mathbf{3}$ & $\mathbf{3}$ & 5 & 6 \\
\hline & Total & $\mathbf{1 2}$ & $\mathbf{1 2}$ & $\mathbf{2 1}$ & $\mathbf{2 3}$ \\
\hline
\end{tabular}

The FGD with students were guided by questions around participants' understanding of the term gender, how the sitting arrangement help or inhibit the participation of boys and girls, what kind of teaching approaches encourage equal participation of boys and girls, the provision of equal access to libraries, computers, sports, science laboratories in the schools.

The FGD with teachers included questions on the teachers' understanding of gender, how a gender-responsive school is different and similar to ordinary schools, the emphasis of gender in policies, and how important was it for teachers to be mindful of gender sensitivity. 


\section{Data Analysis}

The observation recordings were analysed for emerging themes. The FGD were recorded and transcribed. The transcribed data were coded and analysed for emerging themes.

\section{FINDINGS and DISCUSSION}

\section{Classroom setting and context}

Students were seated in groups of four and five except in a few classrooms where students were seated in traditional rows facing the blackboard. Groups were formed with a mix of boys and girls although where there are more girls the groups composed of more girls and vice versa. Groups were formed by the class teachers based on ability. In a few classes, most girls were seated towards the front and boys towards the back because girls were shorter than boys.

The classrooms were well lit with natural light and electric bulbs, students were seated comfortably on wooden chairs with tables. A few classrooms were crowded with a large number of students, but generally, the classrooms had between 20-25 students. Some classrooms had overhead projectors fitted from the class ceiling, whiteboard, and chalkboard while most classrooms had only chalkboard and whiteboard. Tables, chairs, walls, and cupboards (in some classrooms), were generally neat with no graffiti and generally tidy.

Some classrooms were decorated with student works, inspirational quotes, and portraits of kings and spiritual personalities, wall magazines, dedicated posters for different subjects on the walls, announcements, class timetable and class cleaning rosters. In a few classrooms, there were pictures of male thinkers and leaders. In a semi-urban Middle Secondary School, there was a row of pictures depicting fictional superheroes with similes written on them pasted on the walls (Examples, Be strong as Thor, Fight like Hulk, Never give up like Wolverine, Be cool as Deadpool, Make decision like Captain America, Like Thanos wait for the right time and make your dream come true). The associated messages reinforce the typical stereotyping of males being strong, decisive, determined, and courageous.

Another example of stereotyping was how groups in classrooms had group names. One such name of a group consisting of only girls was "Girl Gang No Boy Allowed" evident of girls making a statement. The scribbled phrase "I love you" implied a typical adolescent behaviour in terms of expressing emotions between teenage boys and girls.

\section{Pedagogical practice}

In all the classroom observations, teachers mostly stood in the front usually in one place. Teachers were seen to have eye contact with all the students. Teachers only moved about the class to monitor tasks assigned to students after a lesson was delivered. It was observed that not much discussion, interaction, or feedback happened during the monitoring. Although students were seated in groups, the teaching-learning methods used by the teachers were mostly traditional lecture, explanation, and question answer. $16.6 \%$ of teachers used 
PowerPoint presentations, $8.3 \%$ of teachers used a YouTube video related to the topic, chart papers to assign group work for presentation. Although well intended, it appeared artificial as such a classroom environment did not exist every day.

Normally lessons are well organized and presented within time, teachers are unable to put extra effort to encourage quiet students, especially girls because in almost all the classes girls appeared submissive, shy, quiet, while boys were seen to ask clarifying questions, raise hands frequently to answer questions. In an urban school although, the teacher provided equal opportunity to boys and girls to comment and answer, the boys were proactive, confident, and vocal in answering questions. A boy, for instance, volunteered to lead brain break during the process of the lesson on day two's observation. Another boy requested for extra time during group work. The teacher could call boys by names to share their understanding of the topic. The girls were silent. However, a girl shared her view without the teacher having to call her. Another girl raised her hand but the teacher could not see her and lost the opportunity to speak. During the individual work, the girls were active and fully engaged. The individual work was reading a topic related to the lesson. The girls were found reading attentively. The students shout out "bingo" upon completion of their task. The boys and girls interacted with each other. A boy, for example, leaned a book to a girl. The teacher encouraged both boys and girls but the boys were confident and proactive. The girls were shy, silent, and less confident. However, there were a few girls who were confident and shared their views on the lesson.

In congested classrooms where students sat in traditional rows, the teacher could not move around the class freely. The teacher encouraged the students' shoulder partner to discuss during the discussion. However, based on the sex-segregated sitting arrangement, the student's discussion was limited within one sex. In a remote school, presentations were made by a group representative nominated by the members. Usually, girls came forward to present. In a couple of schools, the teachers seem to have been influenced by the observations because in observation on Day 2, which was after a day's gap, intended calling out to girls to present or answer questions or "now it's the girls turn, next will be boys turn" were seen. In other schools, the teachers encouraged both boys and girls, but boys were more confident and proactive. The girls were shy, silent, and less confident. But during the debrief meeting with the principal and the teacher, they shared that girls were disciplined, hardworking, studious, and were academically better than boys.

\section{Classroom use of language}

Teachers were seen to use informal and derogatory language. Example, a teacher teaching English often used words, such as "guys", another teacher used a mix of English and Dzongkha. Sometimes Hindi was seen to be used too, example, "Are ho samba", a phrase coming from a Hindi cinema where the actor uses it to order others carried a gendered message of "maleness". In a semi-urban school, a teacher was observed using derogative word "Deu" (meaning idiot) and "Zedu" (meaning useless) to refer to a boy who was not as active as other students in the 
class. The phrase in itself does not imply gendered meaning but carries a condescending connotation. It may affect the particular learner's self-esteem.

Teachers were observed to use words and phrases from other languages to reinforce participation or correct answer, or to create fun and excitement in the class. For example, a teacher used the French word (Sawa-Sawa and We-We) to gain a student's attention. It roughly translated to "class, class, yes, yes" as was taught to teachers during a nationwide workshop on new methods of teaching, to draw students' attention. The teacher exhibited a lot of energy, enough eye contact with students, and good use of gestures and had a good command of the English language. Mindful use of classroom language by teachers can support direct instruction or create a conducive learning environment. In most of the classes observed, girls seemed confident and participated actively. In one class, the teacher had a good rapport with students, and classroom interactions appeared casual when the teacher used derogatory words to address boys who were not very active in the class. The words may not imply gender meanings, but it might affect the learner's self-esteem.

\section{Understanding gender and gender concepts}

The FGD revealed a limited understanding of gender among participants. The concepts that were known among the teachers generally included gender terms such as 'gender equality, gender discrimination, gender equity, gender bias, gender is male, female, and LGBT'. 8.3\% of female teacher participants believed that "gender is socially constructed because we believe men will not cry only women will cry, men are stronger and women are weak". $16.7 \%$ of male teacher participants said, "Gender means confrontational attitudes towards men". All male and female teachers shared that, " $a$ woman has to live nine lives to be born a man". $22.2 \%$ of male teachers and $16.6 \%$ of female teacher participants were confused with the words 'Gender' and 'Sex' and consider gender and sex as synonyms. 8.3\% of female teachers remarked, "Gender means male and female". Discussions around the concepts reveal mixed understanding, such as giving equal opportunities for boys and girls meant gender equality as well as equity and addressing gender discrimination. During FGD, all teacher agreed that "there is a lack of gender sensitivity training in teacher training courses to sensitize teachers and school leaders to gender concerns". None of the teachers has studied gender in education.

During the FGD, the teachers shared extensively about how social and parental expectations and peer pressure influence the behaviour and attitude of children. $66.6 \%$ of teachers said that "parents and society believe that girls do not need to study as much as boys because they can get married and they will be supported by their husbands. It is all right for girls to have basic education. Girls can become teachers and nurses. Boys should become doctors and engineers". Upon birth, society stamps how a boy and girl should behave, talk, dress up including colour choices and toys. One female teacher shared an example "girls can grow hair, wear a red, pink and floral dress. Can play with toys like Barbie dolls, can play the role of a mother or sister or daughter in playing family games. Boys can play with guns, plough, bow and arrow, and 
play football". Society at large and family, in particular, incite beliefs in children which are passed down generations. It is hard for children not to develop a particular belief, behaviour, and look forward to shouldering a certain kind of responsibility in society as they enter adulthood. While there is a deep respect for culture and tradition, beliefs that create inequality and injustice that do not add value to the development and progress of humankind requires attention.

\section{Gender-responsive versus ordinary schools}

$37.5 \%$ of teachers said that "they were hearing words 'gender-responsive' verses 'ordinary schools' for the first time in their teaching career". $22.2 \%$ of teachers mentioned that "a genderresponsive school will be one where students are respected, students can reach out to each other and ensuring equality for boys and girls in co-curricular activities". $8.3 \%$ of teachers said that "gender-responsive schools are where students are told that all skills and knowledge are relevant to both boys and skills and where there is respect for intellectual power and capability in both men and women. Whereas an ordinary school will be those where there are gender biases, discrimination, backward in thinking". 8.3\% of female teachers shared examples of how teachers of ordinary schools remind boys and girls how to behave by saying "Do not behave like a boy. Don't behave like a girl. Be like a girl. Try to be strong, boys are supposed to be strong."

\section{Emphasis of gender in policy}

Respondents at the FGDs reported not being aware of the explicit mention of gender in the school rules and policies. Participants paused to answer this question. Upon probing, seven teacher participants of the FGDs said that an emphasis on "mass participation" was there but they were not sure if it was a policy to encourage equal participation of both boys and girls. Two teacher participants (one male and one female teacher) mentioned that "we focused more on teaching and we are least bothered on the policy. So far, our policy was all taken care of by the school management. Our job is to do well in the classroom". During FGD it was known that, while it was not a policy in the schools, the school conduct all co-curricular activities class-wise to encourage maximum participation. In all schools, it was found that leadership responsibilities such as school captainship and house captainship were equally represented by both boys and girls. During FCD all teacher participants shared "the school has a policy on disciplinary issues, disaster management, education policy but they have not heard about gender policy in school. They would like to know what gender policy is from the researchers so that we can incorporate it into our school policy".

\section{Teachers being mindful of gender sensitivity}

When asked how important it was for teachers to be mindful of gender sensitivity, all teacher participants shared about the current scenario of student participation programs and activities in the schools. Girls are more forthcoming in cultural programs while boys are more forthcoming in games and sports. All teacher participants said, "in classroom participation, girls are usually shy, not confident and maybe are worried that they will be criticized and often boys participate 
in the class". $41.6 \%$ of teachers said, "I assign muscular tasks to boys which I think are heavy and require physical strength to boys". The pre-conceived notion among the students about boys and girls seem to be brought from home and family. As an example, one teacher said that "when I send my daughter to shop I go with her when I send my son, I only instruct him not to be naughty and break other's things and I don't go with him". It was also shared that in lower classes girls are more active but in higher classes, boys are more active and performed better. $50 \%$ of male teachers and $16.6 \%$ of female teachers shared that 'it was important for teachers to understand the capabilities of both boys and girls and give them confidence, appreciate them, and make students know their potential and capability". 22.2\% of female teachers said that "children should be treated equally to make them feel confident, work collectively and feel positive". $16.6 \%$ of teachers said, "I scold both boys and girls equally. I never differentiate between boys and girls in the school". Similarly, 8.3\% of female teachers said "I never differentiate between boys and girls in the classroom". $8.3 \%$ of male teachers reported that "mentoring students on the importance of acquiring skills for employment and livelihood. There was no stereotyping of trades for either girls or boys". Although participants brought out and shared observations and issues in differences in student participation and achievement, the importance of teachers being gender-sensitive to inform their actions did not come out clearly.

\section{Understanding gender and gender concepts}

All student participants shared about having heard about gender equality between ladies and gents, gender meant being a male or a female, gender equality meant males and females being equal. A male student shared "In olden day boys and girls could not do the same thing but now with technology and mechanization what men can do women can do too, so this is gender equality". A female student participant said that "they knew gender equality and equity but did not know if there was any difference between the two or if they meant the same". $4.3 \%$ of female students shared examples of gender discrimination in society "girls not allowed to make water offering, it was considered bad luck for the archers and that one would lose the game if girls crossed over the bow and arrows when a girl menstruates she was not allowed to touch kitchen utensils or touch pickles lest the pickles do not turn out to proper taste". $4.7 \%$ of male students shared that "dart game, locally known as Khuru which used to be predominantly played by men in the past, but today women to play Khuru for gender equality". $4.3 \%$ of female students shared about participating in an international game as a part of gender participation when she was in class $X$, she saw women players at the games. Still, she said that she feels uneasy to play like boys but feels proud when she can play well. The general understanding of gender among students seems to be influenced by observations made in society and personal experiences. All student said that they have not studied any chapter or topic related to gender or how gender and education are related. The FGD also revealed that there is an absence of explicit reference to gender equality and equity in the school policy which is given in the annual student diary. 
However, teachers believe that schools promote "mass participation' of students in cultural, sports, and other co-curricular activities" to support gender equality among the students.

\section{Teaching approaches used by teachers}

FGDs revealed that the popular teaching approaches used by teachers were traditional, such as the lecture method where teachers stand in the front of the class and explain and ask questions while students take down notes, answer questions, and make notes. $11.4 \%$ of students shared that "group work, group projects, discussions in groups helped them learn better. When teachers lectured and asked questions, girls shared that they feared being ridiculed by their classmates or scolded by their teachers and did not participate. When working in groups, they shared that inhibitions were not there and they were able to share their ideas freely". $22.7 \%$ of students said that "they felt encouraged and happy when teachers invited students to seek clarification and when they respectfully spoke a simple language". All students mentioned that "debates and inter house competitions where both girls and boys are given equal opportunities they participated willingly without anyone having to request or pressurize them". $14.3 \%$ of boys and $8.7 \%$ of girls reported having monthly student meetings, but generally, boys participated more in the discussion and decision making, while girls were shy to talk. The female student participants said, "we request some of our male friends to talk on our behalf when there were some proposals or ideas that touched or appeared important for the girls". This could be a symptom of girls' contributions having been undermined, which when prolonged over a period effect the confidence of girls.

\section{Access to library, laboratories, computers, and sports facilities}

The FGDs revealed that generally there were no problems with toilets, water, class space, sports facilities, library, laboratory, and computers. Some problems that the participants shared were on the access, for example, there were not enough computers for optimal use of students, students share computers and that reduces the time they get to use the computers. In two schools, girls were not able to play basketball due to some incidence of misbehaviour in a past game. $65.2 \%$ of girls said that "girls are not allowed to visit the school academic block during weekends". All the girls shared about how girls missed out on learning during group projects. Usually, it was the boys in the group who would be engaged in internet research for materials for group projects, which they are mostly able to do on weekends when they had no classes to attend. Due to a few incidences that disrupted the school, the whole opportunity of learning for students is missed out. Understanding the educational purpose and value of co-curricular activities for the wholesome development of human beings no school, teacher, school leader, and parent will fail to put in proper measures to support every child to take advantage of the facilities for the overall growth and development. There are examples of support from the school made consciously to support the less noticed ones. For example, in one school a girl has been appointed prayer captain, a position normally served by boy students. The newly 
appointed prayer captain shared about her experience, having felt very nervous knowing that prayer captainship was a boys' domain by practice in most schools. But support from the school leaders, teachers, and other students, both boys and girls, the new prayer captain enjoys leading the prayer sessions in the school. Such stereotypes can be broken in educational institutions such as schools. Through FGD, it was revealed that there is unequal access to libraries, laboratories, computers, and sports facilities in the schools.

The result and findings of the study are consistent with the findings of a previous similar study done on gender-responsive pedagogy awareness and practice: A case of higher secondary school under Thimphu Thromde in Bhutan by Dorji (2020). The findings from the present as well as the past studies had not reached the attention of teachers, educational policymakers and teacher training colleges within Bhutan because of a lack of professional forums and platforms for scholarly discourse. The smallness of the sample size could be a limiting factor in publicizing in the research because of the engagement of much fewer subjects, and that the research was based in classroom practice.

\section{CONCLUSION}

None of the schools covered gender themes in the school policy. Teachers and students had limited understanding and awareness about gender. The classroom setups and classroom instruction and interaction did not address gender fairly. There is unequal access to libraries, laboratories, computers, and sports facilities for both boys and girls. Therefore, it calls for integrating gender into educational programs and school activities. The teachers need gender sensitization through awareness programs and in-service professional development to reshape the pedagogical practices of teachers. Teacher education programs should be enriched with gender in education.

\section{Limitation and Implication of the Study}

It was not within the ability of the researchers to have an equal number of male and female respondents. The qualitative nature of the study limits coverage of participants. Future research in the same field is recommended with mixed-method approach including surveys with students, teachers, and policymakers; focus group discussions with parents, teachers and students; and interviews with policymakers and school leaders. It is also recommended to include the faculty and students of the Colleges of Education to find out the relationship between the practice of in-service teachers and the preparation of pre-service teachers.

\section{Acknowledgement}

The researchers would like to thank the:

i. Royal Education Council and Ministry of Education for rendering administrative support;

ii. Dzongkhag and Thromde Education Offices, principals, teachers, and students for their cooperation and necessary support. 


\section{Funding information}

The research was undertaken as a UNESCO participation programme 9290114044: Gender Sensitivity in Curricular and Pedagogical Practice in Bhutanese Middle and Higher Secondary School and Tertiary Institutions.

\section{REFERENCES}

ADB. (2014). Bhutan Gender Equality Diagnostic of Selected Sectors. Manila, Philippines: ADB. BCSEA. (2019). Launch of Bhutan PISA-D National Report. Thimphu, Bhutan: BCSEA. BCSEA. (2014). Pupil Performance Report 2014, 2017. Thimphu, Bhutan: BCSEA.

Chisamy, G., Dejaeghere, J., Kendall, N., \& Khan, M. A. (2011). Gender and Education for All: Progress and Problems in achieving gender equity. International Journal of Educational Development, 2012, 1-12.

Dorji, T. (2020). Gender Responsive Pedagogy Awareness and Practices: A Case Study of a Higher Secondary School under Thimphu Thromde, Bhutan. International Journal of Linguistics and Translation Studies, 1(2), 100-111.

Dorji, T. (2017). Gender Gap in the Constituent Colleges of the Royal University of BhutanReasons and Implications for Gender Equality. RABSEL the CERD Educational Journal, $18(2), 61-82$.

Duckworth, A.L., \& Seligman, M.E.P. (2006). Self-discipline gives girls the edge: gender in selfdiscipline, grades and achievement test scores. Journal of Educational Psychology, 98(1), 198-208.

FAWE. (2005). Gender Responsive Pedagogy: A Teacher's Handbook. Nairobi, Kenya: FAWE.

GNHC. (2019). Twelfth Five Year Plan 2018-2023: Just, Harmonious and Sustainable Society through Enhanced Decentralization. Thimphu, Bhutan: GNHC.

Hodges, A. (2001). Children's and Women's Rights in Nigeria: A Wake-up call. Situation assessment and analysis. Abuja, Nigeria: National Planning Commission and UNCIEF.

iDiscoveri Education and the REC. (2009). The Quality of School Education in Bhutan: Reality and Opportunities. Thimphu, Bhutan: REC.

Marks, G.N. (2007). Accounting for the gender gap in reading and mathematics: evidence from 31 countries. Oxford Review Education, 34 (1), 1-21.

MoE. (2014). Bhutan Education Blueprint 2014 - 2024: Rethinking Education. Thimphu, Bhutan: MoE.

National Statistics Bureau of Bhutan \& Asian Development Bank. (2012). Bhutan Living Standards Survey 2012 Report. Thimphu, Bhutan: NSB \& ADB.

NSB. (2017). Population and Housing Census of Bhutan 2017. Thimphu, Bhutan: NSB. 
Reeves, H., \& Baden, S. (2000). Gender and Development: Concepts and Definitions Prepared for the Department for International Development (DFID) for its gender mainstreaming intranet resource. Brighton, UK: Institute of Development Studies (University of Sussex).

REC. (2010 \& 2011). Annual Status of Student Learning. Thimphu, Bhutan: REC.

UNDP. (2018). Human Development Indices and Indicators 2018 Statistical Update. New York, USA: UNDP.

UNESCO. (2000). World Education Forum-Framework for Action. Dakar, Senegal: UNESCO.

UNESCO. (2004). Gender Sensitivity: A training manual for sensitizing education managers, curriculum and material developers and media professional to gender concerns. France: UNESCO.

UNESCO. (2009). Gender in Education Network in Asia-Pacific (GENIA) Toolkit: Promoting Gender Equality in Education. Bangkok, Thailand: UNESCO.

UNESCO. (2014). Teaching and Learning: Achieving quality for all. France: UNESCO.

UNICEF. (2012). BMIS 2010 Thematic Analyses Series. Thimphu, Bhutan: UNICEF Bhutan.

UNICEF. (2017). Annual Report 2017 Gender Equality and Rights. Kathmandu, Nepal: UNICEF.

Wamahiu, S.P. (1997). The Empowerment of Women through Functional Literacy and the Education of the Girl-Child: Report of the African Conference in the Empowerment of Women through Functional Literacy and the Education of the girl-child. Nairobi, Kenya: UNICEF ESARO.

Warrington, M., \& Younger, M. (2020). The Other Side of the Gender Gap, Gender and Education, 12 (4), 493-508. 